\title{
Modification of Combined Effect of Radiation and Sodium Chloride on Microorganisms by Chemical Agents during Irradiation
}

\author{
By Mitsuo Namiki*, Yoshishige Okazawa* and Akira Matsuyama** \\ *The Institute of Physical and Chemical Research; **Department of Agricultural Chemisty, \\ Faculty of Agriculture, The University of Tokyo \\ Received August 16, 1960
}

\begin{abstract}
Effects of various chemical agents on the synergistic action of $\mathrm{NaCl}$ to the radiation inactivation of bacteria and yeast were studied. The remarkable modification of the radiation lethal effect by some reagents is considered to be a strong evidence for an indirect nature of $\mathrm{NaCl}$ synergistic action during irradiation. Most of these modification effects were restricted to the actions during irradiation, supporting the free radical hypothesis in which the short-life active species formed by radiation were considered to attack bacterial cells. Furthermore, pre-irradiation effects under various conditions suggest that the enhancement of radiation lethal effect by $\mathrm{NaCl}$ may involve the intracellular events.
\end{abstract}

\section{INTRODUCTION}

Some inorganic salts such as $\mathrm{NaCl}, \mathrm{KCl}$, other halides etc. were found to enhance the radiation lethal effect on microorganisms, and in order to elucidate the possible mechanism of these salt actions during and/or after irradiation, a series of radiobiological and radiochemical studies have been carried out in this laboratory ${ }^{1 \sim 4)}$. As described in the previous paper $^{3)}$ concerning some physiological aspect of $\mathrm{NaCl}$ synergistic action during irradiation (NSA), it has been suggested that the modification of the bacterial radiosensitivity by $\mathrm{NaCl}$ is based on the indirect action of active species, probably $\mathrm{Cl}$ radicals, formed by radiations. In this paper, data regarding the actions of chemical agents on NSA to elucidate an in-

\footnotetext{
Abbreviation, $\mathrm{NS} \Lambda, \mathrm{NaCl}$ synergistic action during irradiation to radiation lethal effect.

1) Y. Okazawa, M. Namiki, S. Yamashita and A. Matsuyama, This Journal, 24, 235 (1960).

2) Y. Okazawa, M. Namiki and A. Matsuyama, ibid., 24, 435 (1960).

3) A. Matsuyama, Y. Okazawa and M. Namiki, J. Japan Radiation Research Soc., 1-2, 98 (1960).

4) M. Namiki, Y. ()kazawa and A.M atsuyama, This Journal. 25, 108 (1961).
}

direct nature of this phenomenon were presented, and such actions of chemical agents were examined whether they are observed only during irradiation or not. The effects of preirradiation on bacterial cells were also described as an evidence for involving intracellular events in NSA.

\section{METHODS AND MATERIALS}

Microorganisms Escherichia coli and Zygosaccharomyces soya ZS-5, supplied by the Institute of Applied Microbiology, the University of Tokyo, were used in this study. The survival curve of this bacterial strain was of the exponential type and that of the yeast was of the sigmoidal type.

Gamma irradiation Irradiation was performed by using a ${ }^{60} \mathrm{Co}$ source of about 220 curies in the Institute of Physical and Chemical Research as described previously $^{1)}$. In the case of bacteria the radiation dose was $2.4 \times 10^{1} \mathrm{r}$ (corresponding to $1 \%$ survival dose) at a dose rate of $4.8 \times 10^{4} \mathrm{r} / \mathrm{hr}$ in phosphate buffer, and when distilled water was solely used to suspend bacterial cells, the lower dose of $1.6 \times 10^{4} \mathrm{r}$ was employed, considering the decrease in survivors. The yeast was irradiated in $\mathrm{M} / 15$ phosphate buffer $(\mathrm{pH}$ 6.0) with a dose of $1.2 \times 10^{5} \mathrm{r}$. 
Microbiological procedure Techniques used in this paper were similar to described in the preceding paper ${ }^{1)}$.

The procedure for tests of modifications by various reagents of the combined effect of radiation and $\mathrm{NaCl}$ on $E$. coli was carried out as follows: The cells were grown at $37^{\circ} \mathrm{C}$ for 20 hours by shaking culture, washed twice by centrifugation and resuspended in $\mathrm{M} / 15$ phosphate buffer (pH 7.0). Cell suspensions after appropriate dilution, were mixed with $\mathrm{M} / 15$ phosphate buffer containing the test reagent and then exposed to gamma irradiation at $4 \sim 10^{\circ} \mathrm{C}$. The final cell concentration of the suspensions exposed to irradiation was about $10^{7}$ cells $/ \mathrm{ml}$ in viable counts.

After irradiation, the suspensions were diluted 10 times and then each of $1 \mathrm{ml}$ aliquots was well mixed with $9 \mathrm{ml}$ of melted nutrient agar containing $0.5 \%$ $\mathrm{NaNO}_{3}$, followed by viable counting procedure using graduated pipettes as the incubation tube. Unirradiated control suspensions were treated by the same procedure after they were diluted 100 times more than irradiated suspensions instead of irradiation. Subsequently, the final concentration of control suspensions was about $10^{5} \mathrm{cells} / \mathrm{ml}$. The final reagent concentrations in the nutrient agar decreased to $1 \%$ of the concentrations during irradiation. If toxic influences of test reagents on viable counting had been observed, further dilution was employed to avoid them. In the case of heavy metal salts, glass distilled water was used in place of $\mathrm{M} / 15$ phosphate buffer to suspend bacterial cells. Determinations of modification effects with yeast were carried out similarly to those with the bacterium.

Reagents The reagents used in this work were of G.R. or E.P. grade. Sulfanilamide was recrystalized from ethanol (m.p. $165 \sim 166^{\circ} \mathrm{C}$ ). Purified samples of chloramphenicol, dihydrostreptomycin $\mathrm{H}_{2} \mathrm{SO}_{4}$ salt, sucrose esters and $\mathrm{Na}$ dodecylbenzene sulfonate were kindly supplied by Dr. H. Yonehara in University of Tokyo Meiji Confectionary Co., Dainippon Sugar Manufacturing Co. and Tōhō Chemical Industrial Co., respectively.

\section{RESULTS}

Effects of Chemical Agents on $\mathrm{NaCl}$ Synergistic Action during Irradiation. In order to examine the indirect nature of NSA, effects of various chemical agents on NSA were investigated. Cells were irradiated mostly in $\mathrm{M} / 15$ phosphate buffer containing test reagents, but with salts of heavy metal the glass distilled water was used as a suspension medium. The data obtained were shown in Figs. 1 10. Glucose abolished NSA. The similar effect of glucose was observed with the enhancing action of $\mathrm{KCl}$ (Fig. 1). Amino acids, succinic acid and thiol compounds such as thioglycolate, cys-
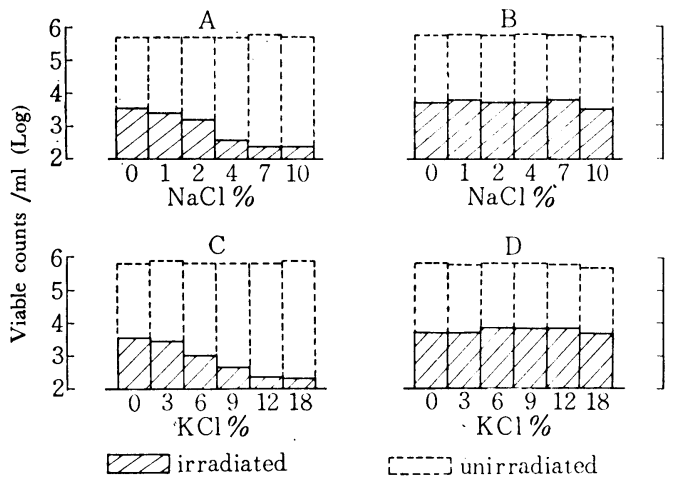

FIG. 1. Effects of glucose during irradiation on $\mathrm{NaCl}$-enhancement of radiation lethal action to $E$. coli.

A \& C, irradiated in glucose-free phosphate buffer; irradiated in $1 \%$ glucose phosphate buffer; radiation dose, $2.4 \times 10^{4} \mathrm{r}$.
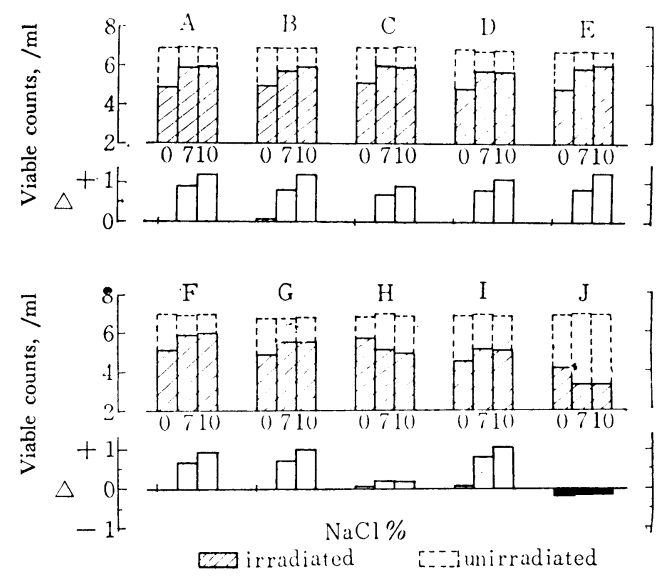

FIG. 2. Effects of thiol compounds, amino acids and carboxylic acids on $\mathrm{NaCl}$-enhancement of radiation lethal action to $E$. coli in phosphate buffer.

A, м/2000 L-cysteine; B, м/3000 glutathione; C, M/2000 Nathioglycolate; D, M/3000 MEA; E, m/2000 AET ; F, m/2000 Lglutamic acid; G, M/2000 L-valine; H, $\mathrm{M} / 1000$ succinic acid; I, $\mathrm{M} / 10$ succinic acid ; J, M/1000 Na-formate ; $\Delta$, see Fig. 4; The histogram of each control was abridged in this figure. 


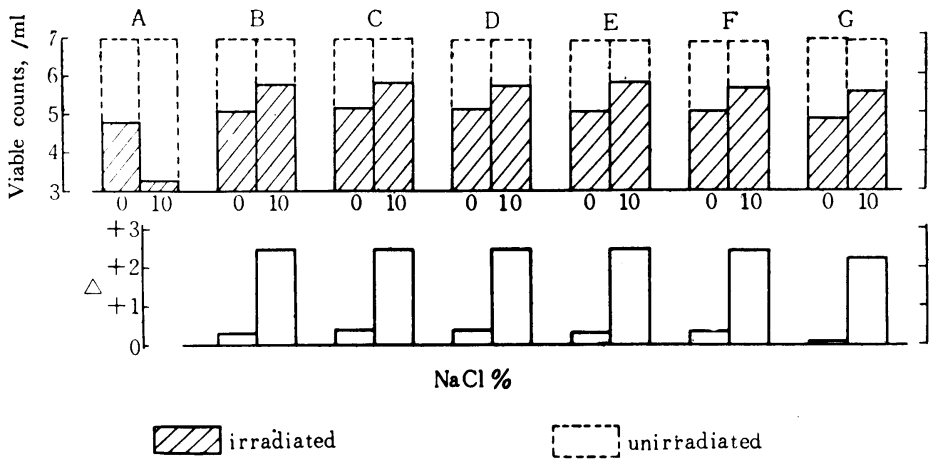

FIG. 3. Effects of natural products on $\mathrm{NaCl}$-enhancement of radiation lethal action to $E$. coli in phosphate buffer.

A, Control ; B, acetone dried powder of $S$. cerevisiae Rasse II (unirradiated cells) $200 \gamma / \mathrm{ml}$; C, commercial yeast extract $200 \mathrm{r} / \mathrm{ml}$; D, acetone dried powder of E. coli $2 \sim 7$ (unirradiated cells) $200 \gamma / \mathrm{ml}$; E, crystalline egg albumin (N.B.C.) $200 \mathrm{r} / \mathrm{ml}$; F, oyster extract syrup; G, oyster extract power $200 \mathrm{r} / \mathrm{ml} ; \Delta$, see Fig. 4.

teine, glutathione, MEA ( $\beta$-mercaptoethylamine) and AET ( $\beta$-aminoethylisothiuronium) were more protective in saline than in NaCl-free buffer (Fig. 2) . Different from protective action of glucose, the protective effect of these reagents was markedly increased with increasing $\mathrm{NaCl}$ concentrations. Even when their protective actions in $\mathrm{NaCl}$-free buffer were negligible, those in saline buffer were remarkable. The effect of formate was not protective, but somewhat toxic, being not associated with NSA. Natural products such as the acetone dried powders of yeast (S. cerevisiae Rase II) and bacterium (E. coli), commercial yeast extracts, oyster extracts, crystalline egg albumin were also protective similarly to the above compounds (Fig. 3).

Phenol exhibited the special type of protection. In the $\mathrm{NaCl}-$ free buffer, the protective action of phenol itself increased with increase of its concentration up to $0.04 \mathrm{M}$. However, in the saline buffer, phenol was synergistic to the radiation lethal effect in concentrations of above $0.02 \mathrm{M}$, although its lower concentrations in saline were still protective (Fig. 4). Then, as shown in Fig. 4, the characteristic type of the combined effect
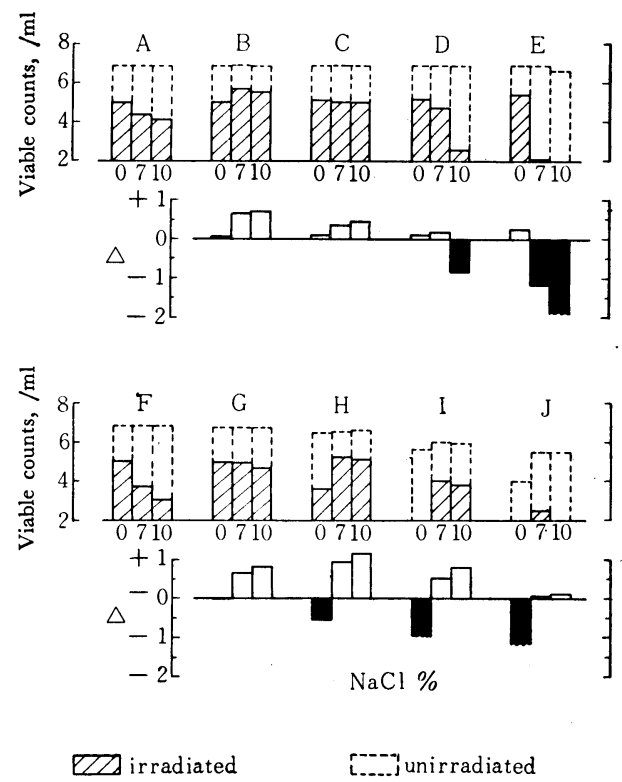

FIG. 4. Effects of phenol and hydrogen peroxide on $\mathrm{NaCl}$-enhancement of radiation lethal action to $E$. coli in phosphate buffer.

Phenol: A, control ; B, $5 / 1,000 \mathrm{M} ; \mathrm{C}, 1 / 100 \mathrm{M}, \mathrm{D}, 2 / 100 \mathrm{M}$; E, $4 / 100 \mathrm{M}$.

Hydrogen peroxide : F, control ; G, 1/10,000 M ; H, 5/10,000 M ; I, $3 / 1,000 \mathrm{M} ; \mathrm{J}, 5 / 1,000 \mathrm{M}$.

$\triangle$ indicates the difference $(\mathrm{Log})$ of decrease in survivors by irradiation between a sample and control. Positive values of $\Delta$ show the protective effect and negative values enhancement of radiation lethal effect. 

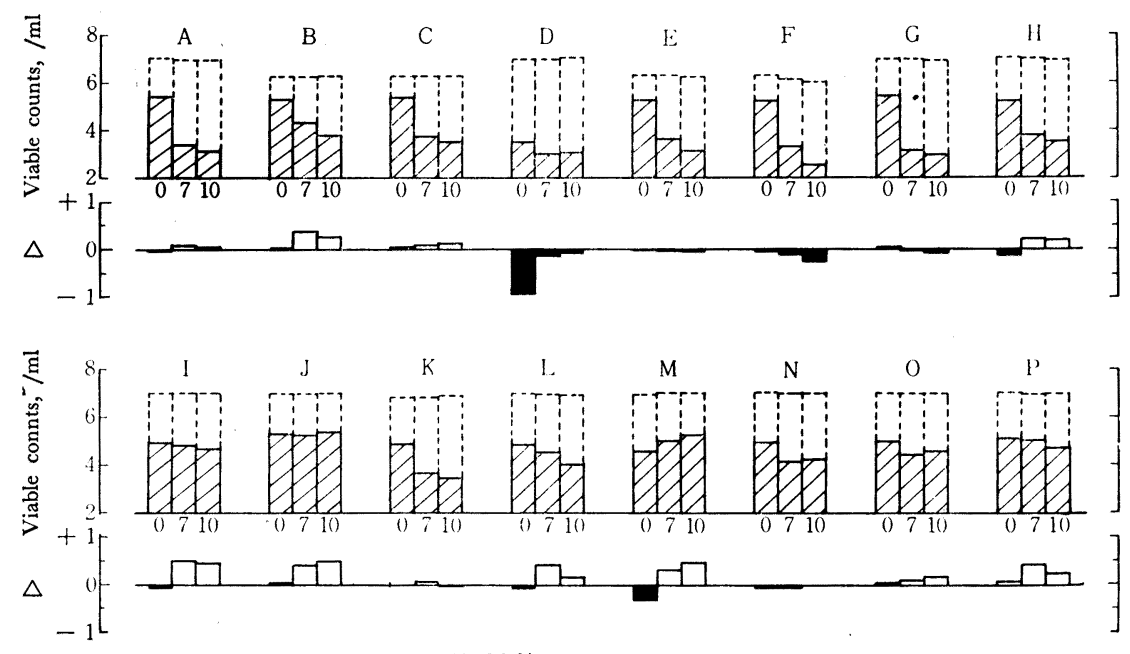

$\mathrm{NaCl} \%$

שृ irradiated

[--:-2unirradiated

FIG. 5. Effects of inorganic salts on $\mathrm{NaCl}-$ enhancement of radiation lethal action to $E$. coli. A, $5 \times 10^{-8} \mathrm{M} \mathrm{FeCl}_{2} ; \quad$ B, $5 \times 10^{-7} \mathrm{M} \mathrm{FeCl}_{2} ;$ C, $5 \times 10^{-6} \mathrm{M} \mathrm{FeCl}_{2} ; \mathrm{D}, 1 \times 10^{-5} \mathrm{M} \mathrm{FeCl}_{2} ; \mathrm{E}, 5 \times 10^{-6} \mathrm{M} \mathrm{FeCl}_{8} ; \mathrm{F}, 5 \times 10^{-5} \mathrm{M}$ $\mathrm{FeCl}_{3} ; \mathrm{G}, 1 \times 10^{-7} \mathrm{M} \mathrm{CuCl}_{2} ; \mathrm{H}, 1 \times 10^{-6} \mathrm{M} \mathrm{CuCl}_{2} ; \mathrm{I}, 1.7 \times 10^{-8} \mathrm{M} \mathrm{FeCl}_{2} ; \mathrm{J}, 1.7 \times 10^{-8} \mathrm{M} \mathrm{FeSO}_{4} ; \mathrm{K}, 1.7 \times 10^{-8} \mathrm{M} \mathrm{FeCl}_{8}$; $\mathrm{L}, 1.7 \times 10^{-8} \mathrm{M} \mathrm{Fe}_{2}\left(\mathrm{SO}_{4}\right) \mathrm{s} ; \mathrm{M}, 1.7 \times 10^{-8} \mathrm{M} \mathrm{CuSO}_{4} ; \mathrm{N}, 1.1 \times 10^{-8} \mathrm{M} \mathrm{MnSO} 4 ; \mathrm{O}, 1.7 \times 10^{-8} \mathrm{M} \mathrm{MnSO}_{4} ; \mathrm{P}, 2.5 \times 10^{-8} \mathrm{M}$ $\mathrm{MnSO}_{4} ; \Delta$, See Fig. 4.

$\mathrm{A} \sim \mathrm{H}$, in distilled water; I $\sim \mathrm{P}$, in $\mathrm{M} / 15$ phosphate buffer. The histogram of each control was abridged in this figure.
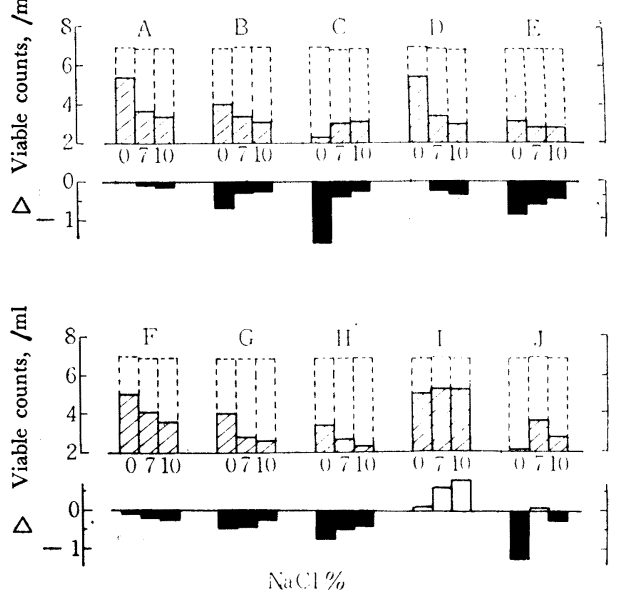

EZz irradiated [...... unirradiated

FIG. 6. Effects of chloral hydrate, chloroform and potassium iodide on $\mathrm{NaCl}$-enhancement of radiation lethal action to $E$. coli in $M / 15$ phosphate buffer.

Chloral hydrate: $\Lambda, 10^{-4} \mathrm{M} ; \mathrm{B}, 10^{-3} \mathrm{M} ; \mathrm{C}, 10^{-2} \mathrm{M}$

Chloroform: D, $6.25 \times 10^{-4} \mathrm{M}, \mathrm{E}, 5 \times 10^{-3} \mathrm{M}$

$\mathrm{KI}: \mathrm{F}, 10^{-4} \mathrm{M} ; \mathrm{G}, 5 \times 10^{-4} \mathrm{M} ; \mathrm{H}, 7.5 \times 10^{-4} \mathrm{M}$

KI+L-glutamate : I, $5 \times 10^{-4} \mathrm{M}+10^{-2} \mathrm{M}: \mathrm{J}, 1.25 \times 10^{-3} \mathrm{M}+10^{-2} \mathrm{M}$ $\triangle$, see Fig. 4; The histogram of each control was abridged in this figure. of phenol and $\mathrm{NaCl}$ was observed with increasing their concentrations, when bacteria irradiated with a constant dose (for about $1 \%$ survival).

On the other hand, an effect of hydrogen peroxide was protective in the saline buffer, while it was synergistic in the $\mathrm{NaCl}$-free buffer (Fig. 4). In lower concentrations of hydrogen peroxide, for example at $\mathrm{M} / 10,000$, it was found to be more effective to protect cells against NSA than to enhance the radiation lethal effect in $\mathrm{NaCl}$-free buffer. Copper salts such as $\mathrm{CuCl}_{2}$ and $\mathrm{CuSO}_{4}$ had the effect of the same type as $\mathrm{H}_{2} \mathrm{O}_{2}$ (Fig. 5). Effects of $\mathrm{FeCl}_{2}$ and $\mathrm{FeSO}_{4}$ were protective and their action was somewhat similar to that of glucose. However, $\mathrm{FeCl}_{3}$ and $\mathrm{Fe}_{2}\left(\mathrm{SO}_{4}\right)_{3}$ exerted no effect. Chloral hydrate and KI enhanced NSA. As shown in Fig. 6, chloroform also showed an enhancing effect, although its synergistic action was decreased with increasing $\mathrm{NaCl}$ concentrations. Sulfanilamide ex- 

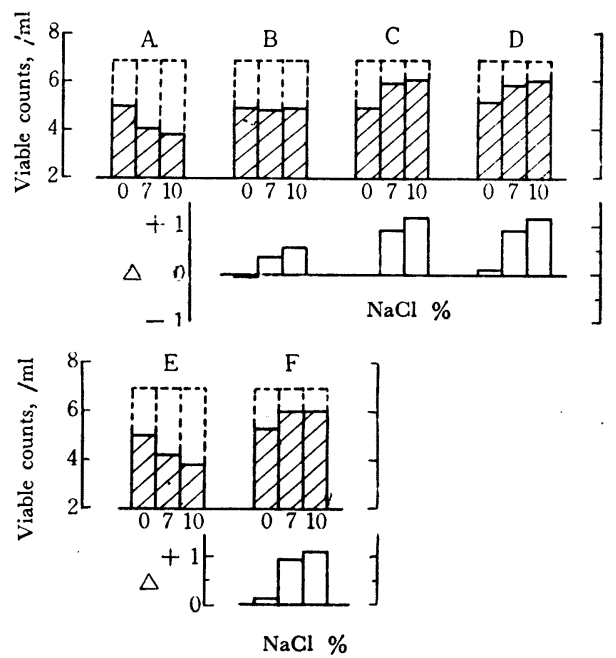
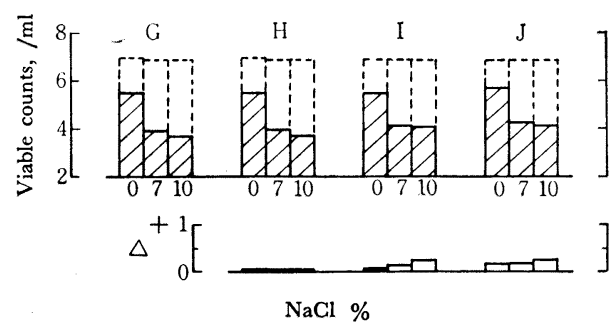

$\square$ irradiated

FIG. 7. Effects of sulfanilamide and chloramphenicol on NaCl-enhancement of radiation lethal action to $E$. coli in $\mathbf{M} / 15$ phosphate buffer.

Sulfanilamide: A, control for $\mathrm{B} \sim \mathrm{D} ; \mathrm{B}, 2 \times 10^{-3} \mathrm{M} ; \mathrm{C}, 2 \times 10^{-4} \mathrm{M} ; \mathrm{D}, 2 \times 10^{-3} \mathrm{M} ; \mathrm{E}$, control for F; F, $6 \times 10^{-3} \mathrm{M}$ Chloramphenicol: G, control ; H, $3 \times 10^{-5} \mathrm{M} ; \mathrm{I}, 1.2 \times 10^{-4} \mathrm{M} ; \mathrm{J}, 3 \times 10^{-4} \mathrm{M}$

$\triangle$, see Fig. 4.
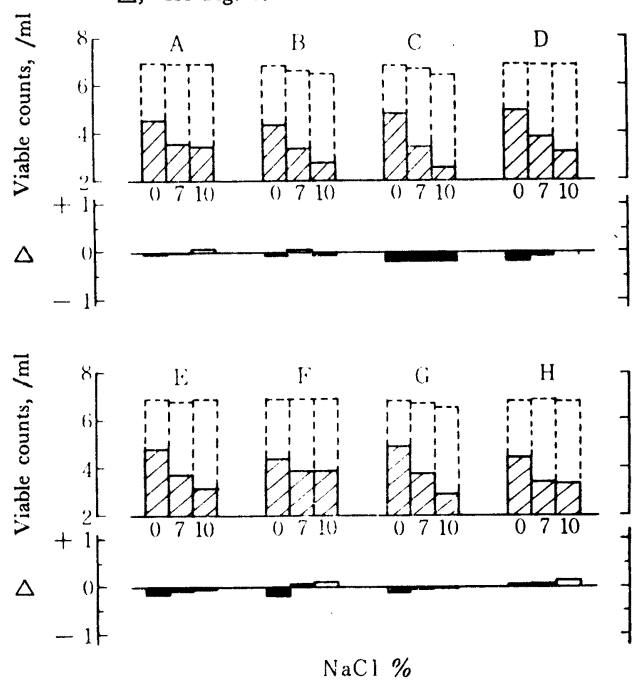

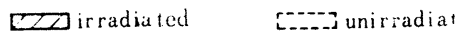

FIG. 8. Effects of emulsifyers and dihydrostreptomycin on $\mathrm{NaCl}$-enhancement of radiation lethal action to $E$. coli in $\mathrm{M} / 15$ phosphate buffer.

A, $0.05 \%$ Tween $80 ; \mathrm{B}, 0.05 \%$ sucrose oleate (crude); C, $0.01 \%$ sucrose laurate (crude); D, $0.01 \%$ sucruse mono-stearate ; E, $0.01 \%$ sucrose di-stearate; F, $0.05 \%$ sucrose tri-stearate; $G, 0.01 \% \mathrm{Na}$ dodecylbenzene sulfonate; $\mathrm{H}, 7.5 \times 10^{-7} \mathrm{M}$ Dihydrostreptomycin $\mathrm{H}_{2} \mathrm{SO}_{4}$ salt

$\triangle$, see Fig. 4; The histogram of each control was abridged in this figure.

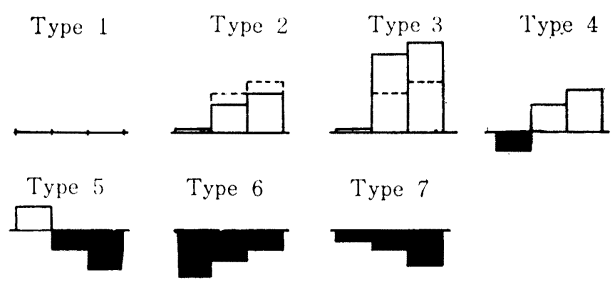

FIG. 9. Schematic grouping of modification by chemical agents of combined effect of radiation and $\mathrm{NaCl}$ on $E$. coli.a,b)

a) Abscissa : 0, 7 and $10 \% \mathrm{NaCl}$ (from left to right)

b) Modification effects were represented in $\Delta$ (see Fig. 4).

c) Dotted line shows the level corresponding to the complete abolishment of the synergistic $\mathrm{NaCl}$ action.

Type 1 Tween 80 , sucrose esters, Na-dodecyl benzene sulfonate, $\mathrm{FeCl}_{\mathbf{8}}$ (dil.), $\mathrm{CuCl}_{\mathbf{2}}$ (dil.)

Type $2^{\mathrm{c})}$ glucose, Chloramphenicol, dihydrostreptomycin, $\mathrm{FeCl}_{2}$,

Type $3^{\text {c) }} \begin{aligned} & \text { FeSO } \\ & \text { thiol compounds, amino acids, succinic acid, sulfanilamide, }\end{aligned}$ natural products containing proteins, phenol (dil.), hydrogen peroxide (dil.)

Type 4 hydrogen peroxide (conc.), $\mathrm{FeCl}_{2}$ (conc.), $\mathrm{FeCl}_{8}$ (conc.), $\mathrm{CuCl}_{2}$ (conc.), $\mathrm{CuSO}_{4}, \mathrm{MnSO}_{4}$

Type 5 phenol (conc.), oxygen

Type 6 KI (conc.), chloral hydrate (conc.), chloroform (conc.), $\mathrm{FeCl}_{2}$ (conc.).

Type $7 \mathrm{KI}$ (dil.), chloral hydrate(dil.), chloroform(dil.), $\mathrm{FeCl}_{\mathbf{8}}$ (conc.)

hibited a remarkable protective effect similar to amino acids and thiol compounds even in very higher toxic concentrations (Fig. 7). Chloramphenicol was not synergistic to the 

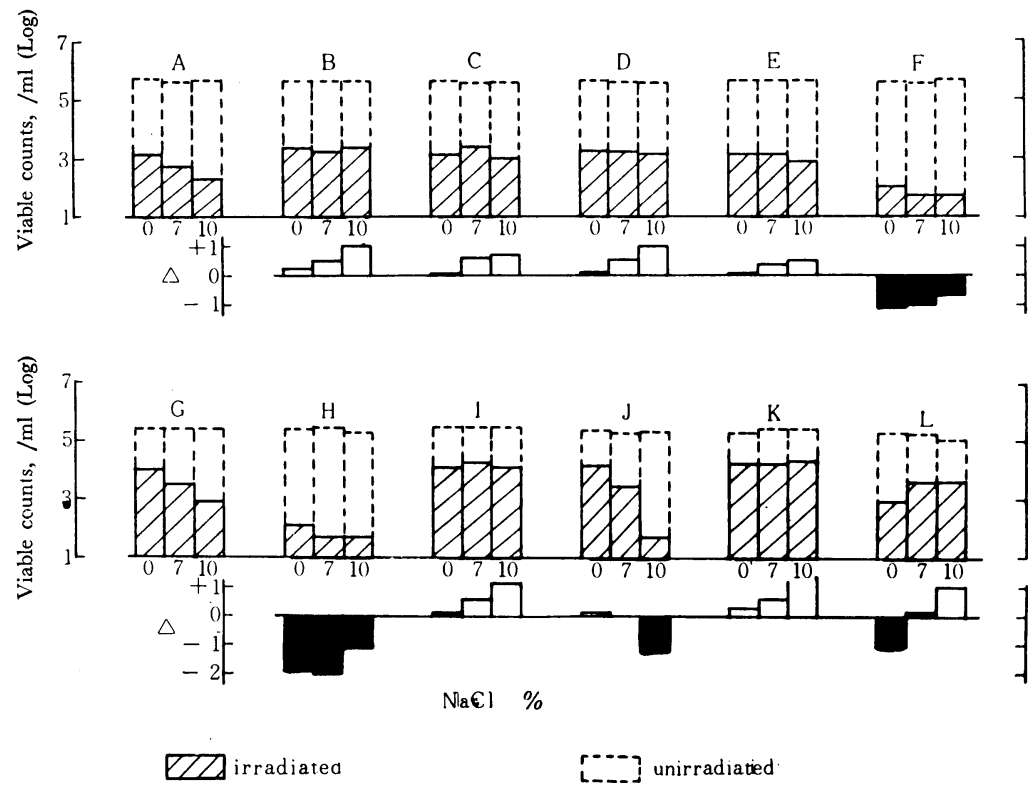

FIG. 10. Effects of reagents on $\mathrm{NaCl}$-enhancement of radiation lethal action to $Z$. soya in $\mathrm{M} / 15$ phosphate buffer.

A, control for $\mathrm{B} \sim \mathrm{F} ; \mathrm{B}, \mathbf{M} / 2000$ L-cysteine; $\mathrm{C}, \mathbf{M} / 2000$ glutamic acid; D, $\mathbf{M} / 2000$ AET; E, $\mathbf{M} / 20$ succinic acid ; F, M/100 chloral hydrate; G, control for $\mathrm{H} \sim \mathrm{L} ; \mathrm{H}, \mathrm{M} / 100$ chloroform; I, M/200 phenol; J, M/50 phenol; K, $1 \times 10^{-4} \mathrm{M}$ hydrogen peroxide; L, $1 \times 10^{-8} \mathrm{M}$ hydrogen peroxide; $\triangle$, see Fig. 4.

combined effect of radiation and $\mathrm{NaCl}$, but rather slightly protective to the resting cells used here.

Besides mentioned above, there were also found many compounds to exert only little influence on NSA in both senses of protection and enhancement. They were surface active agents (Tween 80, sucrose laurate, sucrose oleate and sucrose mono-, di- and tri-stearates), dihydrostreptomycin, etc., although they slightly exhibited the effect similar to type 2 . Consequently, the effects of these various chemical agents are graphically summarized with seven types as shown in Fig. 9. Modification effects similar to the above mentioned with the bacterium were also observed with the yeast, Z. soya. The results are shown in Fig. 10. The effects of phenol and hydrogen peroxide on the yeast were of the same type as those on E. coli. However, the protective action of thiol compounds and succinic acid to the yeast was not so remarkable in comparison with their action to the bacterium. In the case of the yeast, their protective action can be classified into the type 2 (Fig. 9) rather than type 3 .

Effects of Post-treatments with Chemical Agents on NaCl Synergistic Action to Radiation. The posttreatments with some chemical agents which were found to have a considerable modification effect in the experiment mentioned above, were examined in the presence and absence of $\mathrm{NaCl}$ to clear up whether their modification effects are restricted to the time of irradiation or not. The result is shown in Table $I$. The reagents except $0.02 \mathrm{M}$ phenol had no or only slight influence on the viability of $E$. coli after irradiation in contrast with the effects of these reagents during irradiation which are shown in Figs. 1 8. Synergistic actions of 
Table I. Effects of Post-treatments with Ghemical Agents on Viability of $E$. coli Irradiated in M/15 Phosphate Buffers With aND Without 10\% NaCl.

\begin{tabular}{|c|c|c|c|c|c|}
\hline \multirow{3}{*}{$\begin{array}{l}\text { Reagent } \\
\text { added }\end{array}$} & \multirow{3}{*}{ Concentration } & \multicolumn{4}{|c|}{$\begin{array}{c}\text { Final viable counts } \\
\mathrm{NaCl} \% \text { during irradiation } \mathrm{a}\end{array}$} \\
\hline & & \multicolumn{2}{|c|}{0 (Exp. I) } & \multirow{2}{*}{\multicolumn{2}{|c|}{$\begin{array}{l}10 \text { (Exp. II) } \\
\text { tmentb. }\end{array}$}} \\
\hline & & & $\mathrm{NaCl} \%$ & & \\
\hline & & 0 & 10 & 0 & 10 \\
\hline & $\mathbf{M}$ & \multicolumn{2}{|c|}{$\times 10^{4}$ cells $/ \mathrm{ml}$} & \multicolumn{2}{|c|}{$\times 10^{5}$ cells $/ \mathrm{ml}$} \\
\hline None (control) & - & 3.51 & 2.90 & 10.15 & 9.60 \\
\hline L-Cysteine & 0.0005 & 3.11 & 2.82 & 9.50 & 8.88 \\
\hline L-Glutamic acid & 0.0005 & 3.33 & 3.45 & 9.95 & 9.10 \\
\hline MEA & 0.00033 & 3.21 & 2.87 & 10.05 & 9.15 \\
\hline AET & 0.0005 & 2.95 & 2.61 & 10.00 & 8.45 \\
\hline Succinic acid & 0.1 & 3.14 & 3.01 & 10.25 & 9.55 \\
\hline Egg-albumin & $200 \gamma / \mathrm{ml}$ & 3.28 & 3.16 & 9.15 & 9.74 \\
\hline Sulfanilamide & 0.001 & 2.85 & 2.82 & 9.65 & 9.15 \\
\hline Phenol & 0.005 & 2.86 & 2.69 & 9.40 & 7.75 \\
\hline Chloroform & $\begin{array}{l}0.02 \\
0.005\end{array}$ & $\begin{array}{l}2.88 \\
3.13\end{array}$ & $\begin{array}{l}2.61 \\
2.98\end{array}$ & $\begin{array}{l}9.83 \\
9.53\end{array}$ & $\begin{array}{l}0.59 \\
9.10\end{array}$ \\
\hline Chloral hydrate & 0.01 & 3.20 & 2.81 & 9.35 & 8.99 \\
\hline Hydrogen peroxide & 0.0001 & 2.70 & 2.77 & 9.54 & 9.58 \\
\hline & 0.005 & 1.74 & 1.15 & 0.31 & 0.74 \\
\hline
\end{tabular}

$\mathrm{NaCl}$ and KCI were also not abolished by the post-treatment with glucose. Subsequently, it is considered that the remarkable modification effects of these reagents except phenol are not based on their actions after irradiation to irradiated cells. On the other hand, phenol at $0.02 \mathrm{M}$ enhanced the radiation lethal effect when cells were irradiated and post-treated in the presence of $\mathrm{NaCl}$, although it was not effective under the other condition as shown in Table I. $\mathrm{FeCl}_{3}$ also enhanced the total lethal effect of radiation even by the treatment after irradiation (Fig. 12). These results indicate that in the cases of phenol in higher concentrations and $\mathrm{FeCl}_{3}$, different from those of other reagents listed in Table I, their actions after irradiation considerably contribute to the over-all lethal combined effect of radiation and $\mathrm{NaCl}$, although their actions after irradiation are connected with $\mathrm{NaCl}$ action.

Effects of Pre-irradiation on Radiosensitivity of Bacteria. There is a possibility that enhance- ment of radiation lethal effect by $\mathrm{NaCl}$ and its modification by chemical agent may involve the intracellular events. If no intracellular events would be associated with this phenomenon, the survivors or irradiated population should retain their unchanged activity. The effect of pre-irradiation on radiosensitivity of survivors was investigated. Bacterial cells preirradiated in $\mathrm{M} / 15$ phosphate buffer with and without $10 \% \mathrm{NaCl}$ were washed by centrifugation, resuspended in $\mathrm{NaCl}$-free phosphate buffer, and then each $2 \mathrm{ml}$-aliquot of this suspension was added to the $2 \mathrm{ml}$-aliquot of the phosphate buffer changing in $\mathrm{NaCl}$ concentration. The final $\mathrm{NaCl}$ concentrations of these suspensions were $0 \sim 10 \%$ as shown in Fig. 11. Then, these suspensions were subjected to the second irradiation. The pre-irradiation was also carried out in the presence of L-cysteine and phenol.

The results obtained are shown in Fig. 11. There is clearly observed a difference in the 


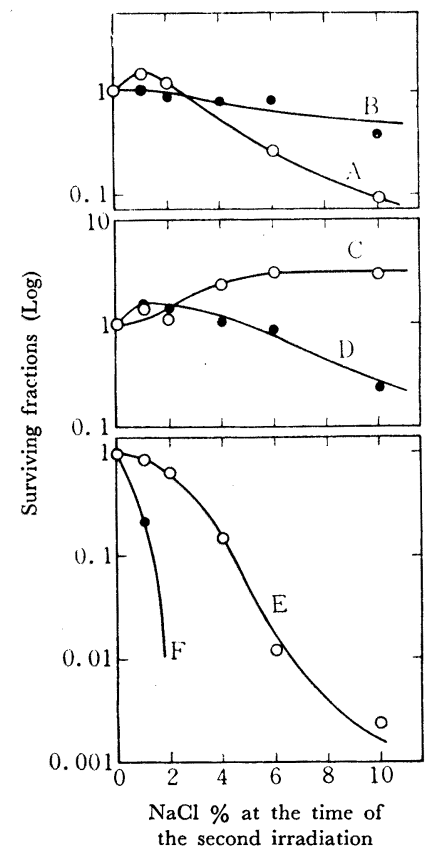

FIG. 11. Effects of pre-irradiation on the combined effect of radiation and $\mathrm{NaCl}$ on $E$. coli.

Dose : the first irradiation, $2.4 \times 10^{4} \mathrm{r}$; the second irradiation, $2.1 \times 10^{4} \mathrm{r}$

Condition of the first irradiation: A, NaCl-free control ; B, $10 \% \mathrm{NaCl} ; \mathrm{C}, \mathrm{M} / 2000 \mathrm{~L}$-cysteine, NaCl-free ; D, M/2000 L-cysteine $+10 \% \mathrm{NaCl} ; \mathrm{E}, \mathrm{M} / 50$ phenol, NaCl-free ; F, $\mathrm{M} / 50$ phenol $+10 \% \mathrm{NaCl}$.

sensitivity to the combined lethal effect of radiation and $\mathrm{NaCl}$ between survivors of bacterial populations pre-irradiated in NaCl-free and $10 \% \mathrm{NaCl}$ buffers. With pre-irradiation in the presence of L-cysteine or phenol, the presence of $\mathrm{NaCl}$ in pre-irradiation also affects the radiosensitivity of survivors. In the presence of $\mathrm{M} / 2000$ L-cysteine, survivors preirradiated without $\mathrm{NaCl}$ decreased their sensitivity to $\mathrm{NaCl}$ action during irradiation with increasing $\mathrm{NaCl}$ concentration, while the sensitivity of survivors pre-irradiated with $10 \% \mathrm{NaCl}$ somewhat increased with increase of $\mathrm{NaCl}$ concentration. In the presence of $0.02 \mathrm{M}$ phenol, pre-irradiation with $\mathrm{NaCl}$ make survivors more sensitive to the combined effect of $\mathrm{NaCl}$ and radiation than that without $\mathrm{NaCl}$. Furthermore, the en- hancement of the radiation leţhal effect by the post-treatment of $\mathrm{FeCl}_{3}$ was more remarkable to cells irradiated in saline than to those irradiated in NaCl-free environment (Fig. 12).

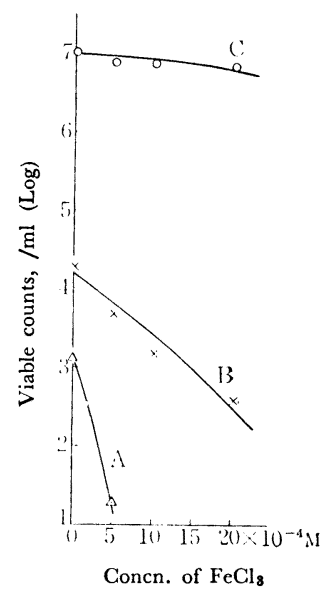

FIG. 12. Effect of post-treatment with ferric chloride on survivors of $E$. coli irradiated in $10 \% \mathrm{NaCl}$ and $\mathrm{NaCl}$-free phosphate buffer.

Post-treatment with $\mathrm{FeCl}_{8}$ : $4^{\circ} \mathrm{C}, 90 \mathrm{~min}$.; $\mathrm{FeCl}_{3}$ was dissolved in distilled water.

A, irradiated with $10 \% \mathrm{NaCl} ; \mathrm{B}$, irradiated without $\mathrm{NaCl}$;

C, unirradiated

\section{DISCUSSION}

To elucidate the complete picture of NSA, some biological aspects of this phenomenon were examined in this study. The remarkable modifications of NSA by various reagents are of great interest as strong evidence for the indirect nature of NSA. As the cells were exposed to irradiation in the resting state, the recovery systems might hardly take part in this phenomenon. The facts that the modification of $\mathrm{NaCl}$ or $\mathrm{KCl}$ synergistic action by several chemical agents and that these effects are restricted to the time of irradiation, support the free radical hypothesis for possible mechanism of enhanced lethal effect, as presented in the preceding paper ${ }^{3)}$. Free radicals formed from $\mathrm{Cl}$ ions and/or chloride molecules, probably Cl radicals, may attack bacterial cells. It is well known in radiation 
chemistry that a part of these free radicals can be scavenged by radical acceptors. Thus, in this phenomenon it is clear that scavenging of free radicals takes place in the solution by protective agents such as amino acids and thiol compounds, etc. which are able to react with toxic free radicals as an intercellular or extracellular events. These events should partly contribute to the remarkable protection of types 2 and 3. The effects of reagents of type 2, ferrous salts and glucose, which abolish the synergistic effect of $\mathrm{NaCl}$ or $\mathrm{KCl}$, can be interpreted by the protection based on such extracellular events. However, the remarkable protection of type 3 such as amino acid, thiol compounds, etc., can not be explaned only by the extracellular events. Moreover, the protective reagents of this type were effective in the saline even in lower concentrations which were not protective in the $\mathrm{NaCl}$-free buffer. Therefore, it is not the case that a series of scavenging reactions of $\mathrm{OH}$ radicals by $\mathrm{Cl}$ ions and of $\mathrm{Cl}$ radicals by protective reagents added, leads to the considerable decrease of toxic species in the bacterial suspension and, subsequently, this radiation chemical change might result in the more remarkable protection in the saline than in the $\mathrm{NaCl}$ free control. Thus, for elucidation of such remarkable protection, it becomes reasonable to postulate that the intracellular events are associated with this remarkable protection. There is another evidence for the involvement of intracellular events in this phenomenon. If, in this case, the protection completely took place as an extracellular events, the activity of pre-irradiated cells would remain unchanged. The experimental clata obtained in this work obviously indicate the influence of preirradiation on the cell sensitivity to the combined effect of radiation and $\mathrm{NaCl}$. This fact illustrating changes in sensitivity of survivors supports the involvement of intracellular events and also suggests that the combined effect of radiation and $\mathrm{NaCl}$ is based on the action of non-single-hit type to cells. Such influence of pre-irradiation in saline was not changed by the treatments with protective agents such as D-glucose (1\%), MEA (M/2000) and L-valine $(\mathrm{M} / 2000)$ between the first and second irradiations ${ }^{5)}$. The intercellular aspects of this phenomenon has been also discussed in the previous paper ${ }^{3)}$. From these discussions it is likely that there is the radiosensitive zone in the saline environment on or near the cell surface. Studies relating to individual effect of each reagent combined with $\mathrm{NaCl}$ during irradiation need further experiments, especially radiation chemical study including of radiolysis of reagents added. Therefore, full discussion of the mechanism will be made in the subsequent paper which will present the data concerning the chemical aspects of the above phenomenon.

Acknowledgements The authors wish to express their sincere thanks to Prof. Y. Sumiki of the University of Tokyo for his guidance. Thanks are also due to Dr. S. Iida of the Institute of Physical and Chemical Research for his encouragement. They are grateful to Misses. H. Ohe, M. Yoshida, and K. Takada for their technical assistance. They are indebted to Dr. H. Yonehara of the Institute of Applied Microbiology, the University of Tokyo, Meiji Confectionary Co., Dainippon Sugar Manufacturing Co., The Nitto Institute of Chemical Research and Toho Chemical Industrial Co. for the samples. This work was supported in part by a Grant in Aid for Scientific Research from the Ministry of Education.

5) A. Matsuyama, Y. Okazawa and M. Namiki, in preparation. 